\title{
Referenciais éticos da educação a distância: uma experiência em cursos da UERGS
}

\author{
Celmar Corrêa de Oliveira \\ Mara Lúcia Fernandes Carneiro ${ }^{2}$
}

RESUMO: Apesar da complexidade da ética, por se constituir em uma ciência prática, podemos utilizar seus princípios no nosso cotidiano, sendo possível aplicá-los também na educação e, em especial, na educação a distância. A observação dos registros dos alunos no fórum de discussão em um ambiente virtual propiciou, em consonância com a perspectiva de pensadores que valorizam a interiorização da reflexão, estabelecer referenciais éticos possíveis de serem adotados por discentes dessa modalidade de educação.

PALAVRAS-CHAVE: Ética, Educação a Distância, Democracia.

\begin{abstract}
Despite the ethics complexity, since it is a practical science, we can use their principles everyday in our lives and apply them in education as well as in distance education. The observation of the students post at a discussion forum in a virtual learning environment let us establish possible ethics references that can be adopted by students when they participate of distance education courses.
\end{abstract}

WORD KEYS: Ethics, Distance Education, Democracy.

\section{A ética na sociedade contemporânea}

As temáticas relacionadas com a ética mostram-se sempre atuais. Ela e a política constituem importantes instrumentos para que os homens façam e aperfeiçoem a sociedade.

Ao oferecer uma reflexão sobre o comportamento social, a ética permite o ordenamento da sociedade visando garantir a coesão social e harmonizar os interesses individuais e coletivos mediante a adoção de procedimentos adequados aos costumes vigentes e a essa reflexão teórica, com validade universal.

Mas como falar em ética na sociedade contemporânea, que apresenta problemas complexos, interligados e interdependentes (MORIN, 2003; LUHMANN,1990) os quais impactam a educação exigindo como produto desse processo um profissional cada vez mais informado e autônomo? (BELLONI,2001)

Como seria essa ética? Como explicá-la? Na educação atual e, em especial na educação a distância, há espaço para se falar em ética? Em caso positivo, qual a importância dessas ações éticas para os sujeitos protagonistas desse cenário, onde a relação espaço-tempo difere fortemente do ensino presencial e os meios tecnológicos se mostram tão relevantes? O agir ético pode contribuir com a sociedade contemporânea no sentido de reduzir sua complexidade?

São essas indagações que nos propomos a discutir aqui, cientes que se trata de uma abordagem preliminar, assim como os estudos sobre Educação a Distância no Ensino Superior também são, ainda, introdutórios. Todavia, esses estudos acrescidos de novas contribuições focadas na reflexão sobre o comportamento humano, poderão tornar-se importante meio de auxilio para o aperfeiçoamento do ensino superior brasileiro.

\footnotetext{
${ }^{1}$ Advogado, Mestre em Direito, Universidade Estadual do Rio Grande do Sul, Professor de Ética em Pesquisa e Legislação em Saúde no Curso de Administração em Saúde. http://www.uergs.edu.br

${ }^{2}$ Engenheira Química. Doutora em Informática na Educação (PGIE/UFRGS), Universidade Estadual do Rio Grande do Sul, Coordenadora do Depto. de Educação a Distância. http://www.uergs.edu.br V. $3 \mathrm{~N}^{\circ} 1$, Maio, 2005
} 
2. O que é ética na perspectiva de pensadores que valorizam a interiorização da reflexão.

A contribuição de Sócrates (470-399 ac) para a filosofia, ao dedicar-se às questões humanas como a vida, a moral e o bem e o mal (SCHNEEWIND, 2001), é tão evidente, que os filósofos são conhecidos como pré ou pós-socráticos. Na ética, conceituada como parte da filosofia que busca refletir sobre o comportamento humano sob o ponto de vista das noções de bem e de mal, de justo e de injusto (COTRIM, 2000) esta contribuição não é menos relevante do que nas demais áreas dessa importante ciência que enfatiza o pensar crítico e racional. Ensinar que a ética não envolve somente costumes e leis exteriores, mas principalmente a convicção pessoal adquirida através da reflexão para compreender o que é justo, fornece elementos para uma ação eticamente correta diante das preocupações que o homem apresenta para consigo e com o seu agir.

Esta interiorização da reflexão também está presente em Kant (1724-1804), pois, segundo o autor, os conteúdos relacionados com a ética têm origem no interior do indivíduo. Assim se refere na obra Crítica da Razão Prática:

\begin{abstract}
A lei moral em mim realça infinitamente o meu valor como inteligência por meio de minha personalidade. Ela me revela uma vida independente da animalidade e também de todo o mundo sensível, pelo menos o quanto se pode inferir da destinação consoante a um fim da minha existência por essa lei, que não está limitada a condições e limites desta vida mas, pelo contrário, estende-se ao infinito (KANT, 1959).
\end{abstract}

Essa reflexão acontece toda vez que o ser humano diante da necessidade de agir corretamente, mesmo com a existência de leis e costumes, indaga sobre qual é o seu dever e diante da possibilidade de poder optar, voluntariamente procede de acordo com que o seu agir se torne uma lei universal. Assim fica realçado o dever como parte fundamental da reflexão que obriga moralmente a consciência livre do sujeito na procura de uma ética de validade universal, apoiada fortemente na igualdade fundamental existente entre os homens. O dever se expressa através do imperativo categórico "Age de tal modo que a máxima da tua vontade possa valer sempre como princípio de uma legislação universal". Pode se extrair dessas considerações que a proposta é que do ser humano, racional e livre emane um agir universal, uma vez que eticamente de acordo e em respeito ao dever é necessário que todos ajam em consonância com esta lei fundamental da razão prática pura.

\title{
3. A importância do agir ético para os sujeitos participantes da EAD e para a sociedade
}

Um dos questionamentos propostos no início deste estudo é se na educação atual e, em especial na Educação a Distância, há espaço para se falar em ética. Em caso positivo qual a importância dessas ações éticas para os sujeitos envolvidos no processo e para a sociedade em geral. Para responder tais indagações é necessário inicialmente explicar como se processa essa modalidade de ensino-aprendizagem.

A educação, através dos processos de aprendizagem e de ensino, envolve a construção constante de informações e conhecimentos. Em uma sala de aula convencional, imagens e sons fazem parte desta troca: os estudantes vêem e ouvem o professor, o professor vê e ouve os seus alunos e os estudantes vêem e ouvem uns aos outros. A comunicação ocorre verbalmente entre professor e estudantes ou combinada com várias mídias, tais como um projetor de transparências, áudio e vídeo, projetor ligado ao monitor do computador e assim por diante (CARNEIRO et al, 2001, p. 511). 
No caso da educação a distância, esta comunicação ocorre entre pessoas que já não estão todas no mesmo local e que necessitam, portanto, de recursos tecnológicos que permitam a superação da distância.

A introdução deste aparato tecnológico no dia a dia do professor é hoje uma realidade. $\mathrm{O}$ barateamento dos computadores pessoais, a disseminação do acesso à Internet e a constante inovação tecnológica trouxeram a tecnologia para dentro da sala de aula, possibilitando outros desenhos antes impossíveis de serem vividos. Este aparato tecnológico propicia vários incrementos nos recursos disponíveis, indo além do ensino presencial e propiciando a expansão da Educação a Distância (EAD), constituindo novos espaços de convivência e aprendizagem (CARNEIRO, 2003).

De forma bastante simplificada, pode-se definir Educação a Distância como o processo educacional que se estabelece quando professor e alunos estão separados geograficamente, mas conectados através de recursos de comunicação (como o correio, o telefone, o fax, a Internet, a videoconferência, etc.).

Moran (2003) define a educação online como "o conjunto de ações de ensinoaprendizagem desenvolvidas por meio de meios telemáticos ${ }^{i}$, como a Internet, a

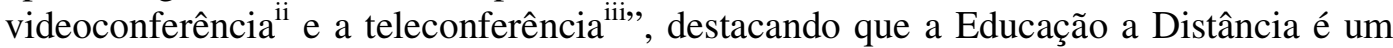
conceito mais amplo. Por exemplo, um curso utilizando o correio tradicional para a troca de materiais entre professor e seus alunos é um curso a distância, mas não poderia ser caracterizado como um curso online.

Atualmente, observamos um movimento de consolidação e expansão da Educação a Distância, à medida que novas alternativas tecnológicas estão sendo incorporadas, viabilizando projetos educativos, tanto por parte de instituições de ensino públicas e privadas, como por parte de empresas e organizações não governamentais. Dessa forma, a EAD passa a ser difundida como uma modalidade de educação com potencialidade para ampliar o acesso à formação acadêmica e profissionalizante, colocando-se como uma alternativa séria de democratização da educação e do saber (GELLER, 2004).

A interação entre o professor e o estudante, na maior parte das vezes, ocorre de modo indireto no espaço (à distância, descontígua) e no tempo (comunicação diferida, não simultânea) o que acrescenta complexidade ao já bastante complexo processo de ensino e aprendizagem à distância. A superação das limitações apresentadas pelo aspecto temporal e espacial nessa modalidade de educação é crucial para a motivação do aluno, condição necessária para a aprendizagem autônoma. Para que este processo se efetive há a necessidade de que esteja centrado no estudante, sujeito capaz de autodirigir e auto-regular o seu processo de aprendizagem e que apresente como características a maturidade, a motivação e um mínimo de habilidades de estudo. (BELLONI, 2001; PALOFF e PRATT, 2004).

Diversos autores (BELLONI, 2001; PETERS, 2001; GARCIA ARETIO, 2001), destacam que os alunos, ao participarem de processos educativos em cursos à distância via Internet, adquirem habilidades mais diversificadas do que os alunos participando de cursos presenciais tradicionais. Em cursos a distância, os alunos precisam utilizar-se de serviços virtuais como os necessários para acesso a informações administrativas, acesso à biblioteca (muitas virtual), realizar o processo de matrícula, comunicar-se com o professor e outros alunos, etc.

A complexidade existente na sociedade atual se expressa em problemas que se apresentam também no processo de ensino e aprendizagem a distância. A compreensão desses problemas e a redução dessa complexidade são medidas necessárias para viabilizar a concretização deste processo educacional. A ética contemporânea é 
pluralista, aceitando diversidades de enfoques, mostrando-se, portanto, compatível com a sociedade atual, tão rica em diversidades.

A ênfase que estamos dando à ética, nas relações sociais e em especial no processo de educação a distância é que por implicar opção individual, requerendo adesão íntima a valores e princípios esta importante área da filosofia se constitui, juntamente com o Direito, em um dos mecanismos de regulação das relações sociais do homem.

Em um Estado Democrático de Direito como o nosso (Art.1 da CF/88 ), o direito está contido na ética, uma vez que as normas jurídicas inspiradas pelos valores escolhidos por aquela sociedade como significativos é que irão incidir sobre os fatos da vida social. $O$ ordenamento jurídico embora não exigindo convicção pessoal e comportando coerção estatal se submete a valores que servem de referenciais a princípios como o da dignidade da pessoa humana e o da liberdade, os quais iluminam as dimensões ética e jurídica de uma sociedade democrática.

$\mathrm{Na}$ aprendizagem realizada com o apoio de um meio virtual também se apresentam alguns referenciais fundamentais à concretização dessa modalidade de educação, os quais permeiam todo o processo e que se situam no plano ético.

\section{Analisando algumas experiências em EAD na UERGS}

A formação de professores e alunos na UERGS está sendo realizada através de cursos totalmente a distância com o uso de um ambiente virtual de aprendizagem (TelEduc) e suporte de videoconferência. Esses cursos têm por objetivo familiarizar os professores no uso dos recursos tecnológicos hoje disponíveis e propiciar a construção de uma cultura de educação a distância na Universidade, que hoje possui Unidades instaladas e conectadas em rede em 24 municípios do Rio Grande do Sul.

$\mathrm{O}$ registro das interações ocorridas ao longo das três primeiras turmas de formação de professores fornece um rico espaço de análise e reflexão sobre a postura ética dos participantes desses cursos a distância. Em especial, analisamos os registros publicados em um dos espaços de discussão assíncronos disponíveis no ambiente virtual, o Fórum de Discussão. Nesses registros buscamos, através dos depoimentos referentes às características julgadas fundamentais a um aluno que participa de um curso a distância, estabelecer em consonância com a literatura disponível, referenciais éticos possíveis de serem adotados por discentes que participam de cursos nessa modalidade de ensino.

O estudo dos depoimentos foi realizado por meio da técnica de análise de conteúdo, realizada em três etapas, conforme Miles e Huberman (1994). A primeira redução do conteúdo dos depoimentos iniciou com a leitura das transcrições e identificação dos temas pré-definidos (condutas dos participantes do processo de aprendizagem nos cursos de EAD) que emergiram dos depoimentos desses alunos.

Para cada registro, os temas investigados foram agrupados e as unidades significativas dos depoimentos (frases, orações, períodos) foram identificadas e transcritas conservando a linguagem do aluno. A seguir, para facilitar comparações, as unidades significativas foram transformadas em linguagem proposta pelos pesquisadores. A redução dos dados envolveu, pois, selecionar, enfocar, simplificar, abstrair, transformar e condensar a informação. A redução foi realizada separadamente pelos pesquisadores e a versão final da redução dos depoimentos foi elaborada por consenso.

A segunda etapa da análise, realizada em conjunto, envolveu a organização e a interpretação de uma matriz com as unidades significativas dos depoimentos dos alunos, 
identificando padrões, verificando contrastes, esclarecendo relações e construindo um entendimento da informação.

A terceira etapa - elaboração de conclusões e verificação - iniciou com a eliminação de unidades significativas redundantes, a anotação e o esclarecimento de relações entre unidades significativas, assim gerando uma descrição da experiência no programa de Educação a distância na UERGS. Essa metodologia demonstrou a plausibilidade da análise realizada com a realização da articulação das informações sobre a experiência dos alunos no programa com a percepção dos professores sobre a aplicação da proposta pedagógica e com a literatura.

\subsection{Características julgadas fundamentais para discentes participantes do processo de ensino-aprendizagem na modalidade a distância na perspectiva dos alunos}

Dos quarenta participantes da terceira turma do curso de Extensão " Conhecendo a EAD e seus recursos", vinte e quatro responderam ao questionamento sobre quais características parecem ser fundamentais a um aluno que participa de um curso a distância.

A grande maioria dos participantes destacou que a participação do aluno é fundamental, pois somente o interesse do aluno sobre o tema permitirá a sua continuidade e também, terá influência direta no seu rendimento (S17; S14 e S6). Além disso, espera-se que esse aluno esteja comprometido com os objetivos do curso (S16; S24; S18 e S22), tratando-os com prioridade. Isto o levará a uma maior disciplina (organização) (S15; S2) que resultará em um envolvimento maior com o curso e o tornará um efetivo participante, proporcionando uma maior interação com o grupo e com os formadores. (S24; S8).

Os alunos mais maduros, optam pelo curso a distância por considerá-lo importante e urgente para as suas vidas (S1; S2). A disposição deve ser total (S1) exigindo perseverança e disciplina (S20), pois os cursos de EAD demandam muito mais tempo e possuem um ritmo diverso (S21) dos cursos presenciais. Há que se considerar também que em um curso a distância, o aluno tem à disposição diversos recursos e pode usá-los quando desejar. (S2).

O aluno de cursos a distância tem um papel ativo. A proposta é dinâmica, participativa e o diálogo é a tônica. A autodisciplina, a organização do tempo e, sobretudo a motivação e senso de responsabilidade (S13; S2; S3 e S 23) são os veículos da inserção e efetivo aproveitamento do aluno em cursos a distância.

Aparentemente isolados, os alunos encontram-se na realidade "conectados" com o mundo (S3). O desenvolvimento de uma postura crítica e participativa do aluno de um curso a distância está diretamente ligado ao seu interesse pelo curso (S14,). É opinando, envolvendo-se, exteriorizando suas idéias, que teremos bons resultados tanto para o aluno como para o professor (S2). Assim, a gente é que se educa, educando e sendo educado na medida em que educar exige, além de autodisciplina, uma boa dose de realismo e coragem para superar contingências institucionais e limitações pessoais (S12).

A ausência da aula presencial pode fazer com que o aluno sempre deixe "para depois", adie as tarefas e termine por não cumpri-las satisfatoriamente. O aluno precisa lembrar que necessita buscar as tarefas e não ficar esperando que o professor as determine como normalmente ocorre nas aulas presenciais. Além disso, o aluno precisa se "conectar", aumentar sua "interatividade", dispor-se à exposição, o que em cursos presenciais nem sempre é necessário ou desejado pelo aluno. Por outro lado, a questão da administração do tempo favorece a realização dos compromissos em um ritmo 
pessoal, o que pode em muitos casos ser favorável (S13; S2), mas, ao mesmo tempo, o aluno não pode esquecer que precisa realizá-las dentro de um tempo definido (S4; S5).

A participação do aluno deve ser estimulada, da mesma forma que na versão presencial. A "postura crítica" na EAD pode tornar-se mais embasada na teoria, mas isto tem que ser construído. As dinâmicas de participação, no entanto, são distintas (S20), como os próprios alunos identificaram em sua participação, nessa condição do curso a distância. $\mathrm{O}$ aluno passa a ter maior responsabilidade sobre seus estudos, pois o processo de aprendizagem é redefinido e apóia-se em uma maior autonomia do aluno. Torna-se necessário ao aluno reservar um período do dia para realizar as suas atividades de estudo. Deve estar "ligado" nas atividades propostas pelo professor e nos comentários e informações "trocadas" nesta "nova sala de aula". A utilização de um ambiente virtual de aprendizagem para a realização de um curso a distância requer que os alunos participantes tenham uma formação superior e, principalmente, estejam habituados a realizar atividades de estudo, ensino e pesquisa, isto é, sejam mais "autodidatas" (S5).

Alguns participantes do curso manifestaram que as diferenças substanciais entre alunos de cursos EAD e alunos de cursos presenciais não são muito evidentes (S1) ou que até que estas diferenças não são substanciais. Nesses cursos, o aluno não precisa prestar atenção quando não quer, porém precisa ter e se prestar a lidar com um computador (S7).

Outros participantes do curso questionaram se alunos de graduação teriam maturidade suficiente para envolverem-se em cursos a distância, mencionando juízo de valores no sentido de que alunos nem sempre têm maturidade suficiente para organizar seu tempo e participar sem a vigilância presencial do professor (S19). Além disso, destacaram que os alunos do primeiro ano dos cursos superiores não têm a maturidade necessária para participar, já que o processo de aprendizagem apóia-se em uma maior autonomia do aluno (S16). Outros afirmaram que, no início, os alunos teriam um pouco de dificuldade, mas (a maioria) adquiriria a autonomia necessária ao longo do curso de graduação (S 21; S 24) e, justamente por exigir um comprometimento maior deles do que o habitual nas aulas presenciais, a educação a distância contribuiria no processo de amadurecimento desses alunos, não só enquanto acadêmicos, mas como profissionais com a tendência de crescimento ao longo do processo (S 16).

\section{2. Analisando as características destacadas}

O estudo teve como objetivo estabelecer referenciais éticos possíveis de serem adotados no cotidiano de discentes da modalidade de educação a distância. Para tal examinamos os registros dos alunos em um dos espaços de discussão assíncronos disponíveis no ambiente virtual, o fórum de discussão e estabelecemos referências em consonância com a perspectiva de pensadores que valorizam a interiorização da reflexão.

Nos registros analisados foram destacadas algumas características que parecem constituir o perfil esperado de um aluno de um curso a distância: participação, interesse, comprometimento, disciplina, envolvimento, opção, perseverança, papel ativo, responsabilidade, postura crítica e autonomia.

Como foi relatado, a grande maioria dos componentes destacou que a participação do aluno é fundamental, pois somente o interesse dele sobre o tema permitirá a sua continuidade no curso de Educação a Distância e terá influência direta no seu rendimento. Além disso, expressaram que o comprometimento do aluno com os objetivos do curso acarretará maior envolvimento e uma maior interação com o grupo e com os formadores. 
Manifestaram ainda que a disposição deva ser total, exigindo perseverança e disciplina, a organização do tempo e, sobretudo a motivação e senso de responsabilidade para a inserção e efetivo aproveitamento do aluno em cursos a distância, pois tais cursos de EAD demandam muito mais tempo e possuem um ritmo diverso dos cursos presenciais

Relataram ainda que os alunos de cursos a distância têm um papel ativo sendo a proposta dinâmica, participativa e o diálogo constituindo-se na tônica. Esta seria a razão de os alunos serem mais maduros, e de optarem pelo curso a distância, pois o consideraram importante $\mathrm{e}$ urgente para as suas vidas. Condicionaram o desenvolvimento de uma postura crítica e participativa de um aluno de curso a distância diretamente ao seu interesse por ele, uma vez que é opinando, envolvendo-se, exteriorizando suas idéias, que os bons resultados serão apresentados tanto para o aluno como para o professor.

Ao observarmos com atenção as expressões recorrentes analisadas, constatamos que envolvem opções que o aluno faz diante de alternativas que se apresentam no processo de aprendizagem. As características realçadas, em verdade, se constituem em uma condição intermediária, necessárias à caminhada que irão desenvolver no processo de aprendizagem. Servem de lastro para que o aluno possa conscientemente, diante da possibilidade de optar, agir corretamente, ou seja, de acordo com o seu dever. Essas afirmações trazem uma forte carga da compreensão Kantiana sobre os deveres que o ser humano deve atender na trajetória da autoperfeição.

\footnotetext{
A menos que realizemos nossos deveres para conosco mesmos, não podemos realizar devidamente nossos deveres para com os outros... Age de tal modo que a máxima da tua vontade possa valer sempre como princípio de uma legislação universal. (KANT, 1959).
}

A autonomia, nos parece, é a característica que melhor expresse as referências feitas pelos discentes, uma vez que envolve um processo de reflexão, no qual a pessoa humana tem a liberdade de optar conscientemente por valores, princípios e normas.A abordagem desenvolvida por Kant sobre a autonomia nos é útil também neste caso, pois pressupõe que somos agentes racionais cuja liberdade transcendental nos tira do domínio da causação natural. Essa autonomia pertence a todo indivíduo, no estado de natureza e também na sociedade.

$\mathrm{Na}$ efetivação desse processo de reflexão é que a ética vai se mostrar particularmente relevante, pois sendo cada pessoa responsável por definir sua ética, torna-se necessário que a definição se dê em harmonia com valores, princípios e normas morais que sejam possíveis de serem adotadas por todos os indivíduos.

\section{Considerações finais}

A sociedade contemporânea apresenta como características o risco e a incerteza em cada decisão que venha a ser adotada. A redução da complexidade dos problemas que se apresentam no cenário da EAD constitui-se em um imperativo para que o processo concretize-se em consonância com os objetivos dessa modalidade de educação.

O perfil do estudante capacitado a ter sucesso na EAD como se conclui é o do sujeito em condições de ser o gestor de seu processo de aprendizagem. 
Esta autonomia necessária ao estudante a distância envolve um processo de reflexão análogo ao existente na ética quando o ser humano exercita sua liberdade em optar conscientemente por uma das possibilidades que se apresentam para sua escolha.

A liberdade é fundamental para a existência da ética. A ética na visão kantiana está centrada em uma lei que os seres humanos impõem a si mesmos, proporcionando a si próprios um motivo para obedecer. Como a ética implica opção individual, escolha ativa, requer do sujeito adesão íntima a valores, princípios e normas morais. Cada pessoa, portanto, é responsável por definir sua ética. Mas como definir essa ética? Embora sejamos livres, conscientes e racionais não há uma fórmula pronta para o agir, restando saber a quem devemos consultar quando precisamos definir o nosso agir?

A reflexão individual e racional de cada sujeito optando voluntariamente por agir de uma maneira universal, na perspectiva Kantiana, ou seja, tomando decisões válidas e vigentes para todos os indivíduos constitui-se em uma alternativa, a ser considerada pelos sujeitos participantes da modalidade de EAD e por todos os componentes da sociedade atual que assim como os problemas da ética apresenta uma hipercomplexidade, a ser permanentemente estudada e compreendida.

\footnotetext{
'A palavra "telemática" teve origem da junção das palavras tele(comunicação) e (infor)mática e, segundo o Houaiss (2001) é "a ciência que trata da transmissão, a longa distância, de informação computadorizada".

ii A videoconferência é um recurso para comunicação entre sistemas conectados através de uma rede, que permite a troca simultânea de áudio e vídeo entre os participantes.

iii A teleconferência envolve a transmissão (unidirecional) de áudio e vídeo, em geral por satélite, a partir de um centro produtor para vários pontos de recepção. A comunicação a partir dos pontos de recepção ocorre pode ocorrer por fax, email ou telefone
}

\section{Referências bibliográficas}

ALMEIDA, Guilherme Assis. Ética e direito: uma perspectiva integrada. São Paulo: Atlas, 2002.

ALVES, Rubem. Entre a ciência e a sapiência: $O$ dilema da Educação. São Paulo: Loyola,2004.

ARISTÓTELES. Ética a Nicômaco.

BARZOTTO, Luis Fernando. A Democracia na Constituição. São Leopoldo: Editora Unisinos, 2003.

BELLONI, Maria Luiza. Educação a Distância. Campinas: Editora Autores Associados, 2001.

CARNEIRO, M. L., MARASCHIN, C., TAROUCO, L. M. R. Interação: fator fundamental em cursos a distância. In: XXIX Congresso Brasileiro de Ensino de Engenharia, 2001, Porto Alegre. Anais do COBENGE 2001. Porto Alegre: ABENGE, 2001, p. 511-515.

CARNEIRO, M.L. O acoplamento tecnológico e a comunicação em rede: inventando outros domínios de aprendizagem. Porto Alegre: UFRGS, 2003 (Tese de doutorado).

COTRIM, Gilberto. Fundamentos da Filosofia. São Paulo: Saraiva, 1999. 
DURKHEIM. Émile. Ética e sociologia da moral. Tradução de Paulo Castanheira. São Paulo: Landy, 2003.

GELLER, Marlise. Educação a distância e estilos cognitivos: construindo um novo olhar sobre os ambientes virtuais. Porto Alegre : UFRGS, 2004. (Tese de doutorado)

KANT, Immanuel. Crítica da Razão Prática. Edições e Publicações Brasil Editora S.A., São Paulo, 1959.

MILES, M. B. e HUBERMAN, A. M. Qualitative data analysis: na expanded sourcebook. Thousand Oaks: Sage, 1994.

MORAN, José Manuel. Contribuições para uma pedagogia da educação online. In:

SILVA, M. (org.) Educação online: teorias, práticas, legislação, formação corporativa. São Paulo, Loyola, 2003. Disponível na Internet:

http://www.eca.usp.br/prof/moran/contrib.htm>. Consultado em 01/03/05.

PALOFF, R. e PRATT, K. O aluno virtual: um guia para trabalhar com estudantes online. Porto Alegre, ArtMed, 2004.

PETERS, Otto. Didática do ensino a distância: experiência e estágio da discussão numa visão internacional. São Leopoldo: Unisinos, 2001.

SÁ, Antonio Lopes de. Ética Profissional. São Paulo: Atlas, 2004.

SCHNEEWIND, J. B. A invenção da autonomia. São Leopoldo. Editora Unisinos, 2001.

TUGENDHAT, Ernst. Lições sobre ética. Rio de Janeiro: Editora Vozes, 2001.

VALLS, Álvaro L.M. O que é ética. São Paulo: editora Brasiliense, 2003. 